\title{
boyd, danah. (2014). It's complicated: the social lives of networked teens. New Haven; London: Yale Universit Press. ${ }^{1}$
}

\author{
Vanina Costa Dias*
}

anah boyd $(\mathrm{sic}),{ }^{2}$ pesquisadora que tem investigado, nos últimos anos, como os jovens usam a mídia social em suas práticas cotidianas, tornou-se especialista em cultura juvenil, participando de discussões sobre as políticas públicas e sobre as práticas da juventude na sociabilidade em rede. Entre suas publicações, encontramos trabalhos que analisam o uso de tecnologias digitais pelos jovens e as implicaçôes das redes sociais para a formação da identidade na juventude. No início de 2014, boyd publicou o livro "It's complicated: the social lives of networked teens", pela Yale University Press. Esse livro_é resultado de oito anos de pesquisa nos quais a autora observou e entrevistou adolescentes de etnias e níveis socioeconômicos distintos, explorando os diferentes aspectos do seu envolvimento com as mídias sociais e outras tecnologias em rede. Entrevistou pais, professores e outras pessoas que trabalham diretamente com adolescentes. Mesmo se tratando da cultura norte-americana, ela acredita que suas análises possam ser relevantes também em outras culturas e contextos.

Diversos estudiosos falam do envolvimento dos jovens com as mídias sociais, mas poucos deles se ocuparam em ouvir os próprios adolescentes sobre o que eles têm a dizer sobre suas vidas on-line e off-line. Buscando preencher essa lacuna, danah boyd dá voz aos adolescentes, refletindo sobre o papel das redes sociais digitais em suas vidas, descrevendo e explicando o modo de convivência em rede de adolescentes para as pessoas que convivem e se preocupam com eles.

\footnotetext{
* Doutoranda em Psicologia e mestra em Educação pela PUC Minas, professora da Fundação Pedro Leopoldo e psicóloga. Fundação Cultural Dr. Pedro Leopoldo, Faculdade de Ciências Humanas Pedro Leo, Fundação Cultural, Faculdade de Ciências Humanas. Endereço: Rua Teófilo Calazans de Barros, 100 - Santo Antônio da Barra, Pedro Leopoldo-MG, Brasil. CEP: 33600000. Telefone: (31) 3686-1461. E-mail: vaninadias@gmail.com.

${ }^{1}$ Recuperado a partir de http://www.danah.org/books/ItsComplicated.pdf.

${ }^{2} \mathrm{PhD}$ em Ciência da Informação pela Universidade da Califórnia, cientista da Computação e investigadora principal na Microsoft Research, em Cambridge, Massachusetts, envolvida em pesquisas sobre mídia social no Data \& Society Research Institute, na Universidade de Nova Iorque e parceira no Berkman Center for Internet and Society da Universidade de Havard. A autora faz questão de que seu nome seja escrito em letras minúsculas.
} 
Nessa investigação, boyd aponta que os adolescentes que conheceu são atraídos pelas mídias sociais ou tecnologias móveis por diversas razôes. Para a maioria deles, é habitual conectar-se com pessoas da própria comunidade por meio das redes sociais. Segundo ela, as redes sociais digitais desempenham um papel crucial na vida dos adolescentes, fornecendo a esses sujeitos um espaço próprio para fazer sentido no mundo, onde podem complementar ou suplementar seus encontros face a face, mudando a essência da forma como os adolescentes buscam seu lugar na sociedade, expressado agora por meio do que ela chama de "público em rede"; públicos reestruturados pelas tecnologias em rede e, como tal, são o espaço construído por meio de tecnologias em rede e também a comunidade imaginada, resultado da interseção de pessoas, tecnologia e prática, construídos em e por meio de redes sociais digitais e outras tecnologias emergentes. Como espaços, os públicos em rede surgem pelas mídias sociais e permitem que as pessoas se reúnam e se conectem, revelando as mesmas funções que os encontros em shoppings ou parques tiveram para as gerações anteriores de adolescentes. Como construção social, conceito que a autora usa citando Leonardi (2012), as redes sociais digitais criaram os públicos em rede que permitem que as pessoas façam parte de uma comunidade mais ampla, permitindo que os adolescentes se vislumbrem como parte de uma comunidade imaginada coletivamente.

boyd relata que as redes sociais fornecem aos adolescentes novas oportunidades de participar na vida pública, e a forma como eles se inserem nesse espaço é o que tem preocupado muitos adultos. Ela chama atenção para quatro ações facilitadoras para a inserção na vida pública proporcionadas pelas redes sociais. São elas:

a) persistência: a durabilidade das expressões e conteúdos on-line;

b) visibilidade: o público potencial que pode testemunhar as práticas on-line;

c) disseminação: a facilidade de compartilhamento; e 4) pesquisabilidade: a capacidade de encontrar conteúdo.

A autora conclui que, mesmo que os adolescentes manipulem as redes sociais para atrair a atenção e aumentar sua visibilidade, não significa que eles sejam igualmente experientes e tenham automaticamente as habilidades para navegar nesses espaços. Para ela, o que se percebe é que os adolescentes se sentem mais confortáveis nas redes sociais do que os adultos. Para os adolescentes, o que é atraente não é a tecnologia, mas a vida pública que ela permite. 
Segundo boyd, o que dificulta a compreensão da relação entre adolescentes e tecnologia é a posição nostálgica dos adultos em supor que suas experiências infantis foram mais ricas, simples e seguras do que as experiências mediadas pela tecnologia vivenciadas hoje pelos jovens, associando o surgimento da tecnologia digital com o declínio social, intelectual e moral. A pesquisa apresentada por ela sugere que o oposto também pode ser verdadeiro.

A autora, ao ser questionada sobre o comportamento dos adolescentes diante das novas tecnologias e seus recursos, explica que eles não estão simplesmente presos à tecnologia, mas estão ali por motivações sociais, estreitando laços de amizade: as interações sociais podem ser uma distração da escola, mas, muitas vezes, não são uma distração da aprendizagem, mostrando que as escolas podem integrar a aprendizagem com experiências sociais para preparar a juventude para ambientes de colaboração e trabalho social por meio do uso das redes sociais. E quando se reúnem nas redes sociais virtuais, buscam estar com seus amigos, sem a supervisão de um adulto, permitindo-lhes privacidade e autonomia. Essas redes não são apenas novos espaços públicos: são, em muitos casos, os espaços onde está o "público" com o qual os adolescentes se reúnem, ainda que fisicamente estejam em casa.

danah boyd contrapõe-se aos relatos da mídia que reforçam a vulnerabilidade de crianças e jovens a riscos que a internet e seus recursos possam lhes trazer, mostrando que esses riscos são exagerados e mal-interpretados e que a chave para entender como a juventude navega nas mídias sociais é se afastar dessas informações, mergulhando na realidade desses jovens. Assim, ao escrever esse livro, danah boyd buscou responder perguntas que a relação entre crianças e jovens com as redes sociais suscitam, tais como o que é novidade nas influências das redes sociais sobre os adolescentes; como a mídia social contribui para a qualidade de vida dos adolescentes; e, finalmente, como os adultos, que não concordam com os resultados da nova tecnologia, poderiam evitar potenciais abusos praticados contra os adolescentes nas redes sociais, sem, contudo, impedir o seu uso e o aproveitamento das possibilidades positivas da rede na vida dos adolescentes.

Ao responder a essas questôes, a autora pretende ajudar seus leitores a entender o que os jovens estão fazendo quando se envolvem com as redes sociais virtuais e suas tentativas de compreender o mundo em torno deles.

Cada capítulo, organizado em torno das diversas preocupações sobre as práticas da juventude com as mídias sociais, pode ser lido como um tópico independente. As temáticas desenvolvidas nos oito capítulos do livro são: a busca da identidade, a necessidade de privacidade, o vício com as redes sociais digitais, 
os perigos relacionados à pedofilia, o bullying ou o cyberbullying, a solução da desigualdade social por meio da mídia, a alfabetização digital e a relação com os seus próprios pares pelas redes sociais.

Essa leitura irá nos oferecer elementos para uma análise mais profunda do que as relações em redes sociais virtuais proporcionam à juventude contemporânea. Contudo a compreensão desse processo pelo qual os adolescentes têm se constituído em suas relações sociais, moldadas por processos tecnológicos e midiáticos que cada vez mais fazem parte de suas vidas, é complexa e não pode ser reduzida a aspectos superficiais. Trata-se de um processo complicado, uma vez que estão em jogo os aspectos sociais, culturais e individuais de cada sujeito.

\section{Referência}

Leonardi, Paul. (2012). Car crashes without cars. Cambridge: MIT Press. 